\title{
Preliminary national report on cystic fibrosis epidemiology in Tunisia: the actual state of affairs
}

\author{
Samia Hamouda ${ }^{1}$, Sondess Hadj Fredj ${ }^{1}$, Sonia Hilioui ${ }^{2}$, Fatma Khalsi ${ }^{2}$, Salma Ben Ameur ${ }^{3}$, \\ Jihene Bouguila ${ }^{4}$, Raoudha Boussoffara ${ }^{5}$, Habib Besbes ${ }^{6}$, Houda Ajmi ${ }^{7}$, Nadia Mattoussi ${ }^{8}$, \\ Taieb Messaoud ${ }^{8}$, Ahmed Mehrezi ${ }^{2}$, Mongia Hachicha ${ }^{3}$, Lamia Boughamoura ${ }^{4}$, \\ Mohamed Taher Sfar ${ }^{5}$, Neji Gueddiche ${ }^{6}$, Saoussen Abroug ${ }^{9}$, Saida Ben Becheur ${ }^{8}$, Sihem Barsaoui ${ }^{8}$, \\ Neji Tebib ${ }^{10}$, Azza Samoud ${ }^{8}$, Najoua Gandoura ${ }^{8}$, Faten Tinsa ${ }^{8}$, Khadija Boussetta ${ }^{8}$
}

1. Bechir Hamza Children's Hospital of Tunis, Department B.

2. Centre Hospitalier Universitaire Mongi Slim.

3. Hedi Chaker Hospital.

4. Centre Hospitalier Universitaire Farhat Hached de Sousse.

5. Taher Sfar Hospital.

6. Hopital Universitaire Fattouma Bourguiba a Monastir.

7. Centre Hospitalier Universitaire Farhat Hached de Sousse.

8. Hopital d'Enfant Bechir Hamza.

9. Sahloul Hopsital.

10. Hopital la Rabta.

\begin{abstract}
Aim: To establish a preliminary national report on clinical and genetic features of cystic fibrosis (CF) in Tunisian children as a first measure for a better health care organization.

Methods: All children with CF diagnosed by positive sweat tests between 1996 and 2015 in children's departments of Tunisian university hospitals were included. Data was recorded at diagnosis and during the follow-up from patients' medical records.

Results: In 12 departments, 123 CF children were collected. The median age at diagnosis was 5 months with a median diagnosis delay of 3 months. CF was revealed mostly by recurrent respiratory tract infections (69.9\%), denutrition (55.2\%), and/ or chronic diarrhea (41.4\%). The mean sweat chloride concentration was $110.9 \mathrm{mmol} / \mathrm{L}$. At least one mutation was found in 95 cases (77.2\%). The most frequent mutations were Phe508del $(\mathrm{n}=58)$ and E1104X $(\mathrm{n}=15)$. Fifty-five patients had a Pseudomonas Aeruginosa chronic colonization at a median age of 30 months. Cirrhosis and diabetes appeared at a mean age of 5.5 and 12.5 years respectively in 4 patients each. Sixty-two patients died at a median age of 8 months. Phe508del mutation and hypotrophy were associated with death $(\mathrm{p}=0.002$ and $\mathrm{p}<0.001$, respectively).
\end{abstract}

Conclusion: $\mathrm{CF}$ is life-shortening in Tunisia. Setting-up appropriate management is urgent.

Keywords: Cystic fibrosis epidemiology, Tunisia.

DOI: https://dx.doi.org/10.4314/ahs.v20i1.51

Cite as: Hamouda S, Fredj SH, Hilioui S, Khalsi F, Ameur SB, Bonguila J, et al. Preliminary national report on cystic fibrosis epidemiology in Tunisia: the actual state of affairs. Afri Health Sci. 2020;20(1):444-52. https:// dx.doi.org/10.4314/ abs.v20i1.51

\section{Corresponding author:}

Samia Hamouda,

Bechir Hamza Children's

Hospital of Tunis, Department B.

Email: samia.hamouda@gmail.com

\section{Introduction}

Cystic fibrosis (CF) is an inherited autosomal-recessive disease caused by a mutation in a gene located in chromosome 7 encoding CF transmembrane conductance regulator (CFTR) protein. Since the first identification of the CFTR gene in 1989, there have been almost 1,900 mu- 
tations reported with variable frequencies depending on ethnic and geographic distribution. CF affects many organs to varying degrees. The lung involvement is frequent and is determinant for the prognosis of patients since it leads to respiratory failure and premature death. ${ }^{1,2}$ The sweat test is the key diagnostic test showing a chloride concentration in sweat (sCl-) above $60 \mathrm{mmol} / \mathrm{L}$. Identifying the CFTR mutation consolidates the CF diagnosis and allows an antenatal screening. ${ }^{3}$

In developed countries, the age of death in CF used to be in the second decade. With the progress achieved in antibiotics, mucoactive therapy, and nutritional supplements, and especially with the policy of instituting CF referral centers, the survival has considerably improved reaching the fourth and fifth decades. The number of CF adults sometimes exceeds the number of CF children when CF healthcare systems are well-established. ${ }^{4,5}$

In Arab societies, few data about CF incidence and CF clinical course are available. Most reports have been of hospital series of relatively few cases, often focusing on clinical aspect at diagnosis and/or addressing the CFTR mutation spectrum, which in itself helps challenge the assumption that $\mathrm{CF}$ is rare among Arabs. ${ }^{6-11}$ This suggests that the CF problem in the Arab region has been poorly evaluated and requires further investigation. In Tunisia, although testing for $\mathrm{CF}$ has been carried out since the 1990s, CF remains under-diagnosed and above all is still life-limiting. In agreement with the Pneumology and Allergology group of the Tunisian Paediatric Society, we aimed to establish a first preliminary national report on the clinical aspects and the genetic specificities of Tunisian CF children in order to have a better assessment of this rare disease in our country. Our final objective was to set a national therapeutic strategy to enhance CF prognosis in Tunisian children.

\section{Methods \\ Study design}

This study was a retrospective review of all children with CF diagnosed from January 1996 to December 2015 in children's departments at the university hospitals of Tunisia: in the North (Bechir Hamza Children's Hospital of Tunis (4 departments), La Rabta Hospital, Mongi Slim
Hospital, Maternity and Paediatrics Centre of Bizerte), in the centre (Farhat Hached Hospital, Sahloul Hospital, Fattouma Bourguiba Hospital, Mohamed Taher Sfar Hospital), and in the South (Hédi Chaker Hospital). CF was confirmed by at least two positive sweat tests or one positive sweat test associated to an identification of a CFTR mutation in patients with relevant clinical manifestations.

The sweat test, available in Bechir Hamza children's Hospital of Tunis and in Farhat Hached Hospital, was carried out by thermal method until 2000. Since 2001, in accordance with Gibson Cooke Method ${ }^{12}$, the sCl- has been measured by semi-quantitative Pilocarpine iontophoresis (Exsudose technique). The sweat test was considered normal if $\mathrm{sCl}-<30 \mathrm{mmol} / \mathrm{L}$, intermediateand to be repeated if the sCl- ranged from 30 to $59 \mathrm{mmol} / \mathrm{L}$, and positive if $\mathrm{sCl}->60 \mathrm{mmol} / \mathrm{L}$.

Genetic analysis was performed in the Biochemistry Laboratory of Bechir Hamza Children's Hospital of Tunis. After parental consent, patients' deoxyribonucleic acid (DNA) was extracted from blood cells using a "salting-out" protocol. Until 2005, the DNA samples were analyzed by the oligonucleotide ligation assay (OLA) kit for the detection of a panel of 33 CF mutations. Since 2006, 1900 mutations have been screened as CFTR gene analysis has included the scanning of the 27 exons and their flanking intronic sequences using denaturing gradient gel electrophoresis (DGGE) and denaturing high-pressure liquid phase chromatography (DHPLC). Samples with abnormal profiles by DGGE and DHPLC have been sequenced. Further details about this procedure were reported in a previous publication. ${ }^{6}$

\section{Data collection}

Data were collected from patients' medical records. For each patient, we noted the age at first symptoms and at diagnosis, the geographical origin, and the existence of consanguinity. We registered the CF circumstances of discovery, the sweat test results, and the CFTR mutation if identified. We also analyzed the respiratory and the extra-respiratory disorders occurring during the monitoring as well as the results of the different investigations made including imaging, microbiology and lung function tests if performed. The possible death and its cause were reported. 


\section{Statistical analysis}

This study was cross-sectional and descriptive. The data were entered using Excel software as qualitative and quantitative values. Statistical analysis was performed using Statistical Package for the Social Sciences (SPSS) version 18.0. The variables were expressed as numbers, percentages, or median, unless otherwise specified. They were compared through the use of the Chi-square test. The Chi-square test associations were appropriate. P-value less than 0.05 was considered statistically significant.

\section{Results}

\section{Demographic data}

In Tunisia, detection for CF has been increasing gradually over the last 20 years (Figure 1). During this period, we diagnosed 123 patients from the children's departments in the North $(n=66)$, the centre $(n=33)$, and the south $(n=24)$, but they originally came mostly from the south where the consanguinity rate was highest among patients' families (consanguinity rate: patients coming from the north $(n=44): 61.3 \%$; from the centre $(n=32): 56.2 \%$; and from the south $(n=47): 76.6 \%)$. The consanguinity was present in $65.8 \%(n=81)$ of all cases. Patients were divided into 71 males and 52 females. The median age was two months at first symptoms [extremes: 1 day; 6 years] and five months at diagnosis [extremes: 1 month; 14 years]. The median time for diagnosis was three months [extremes: 5 days; 12 years] (Figure 2).

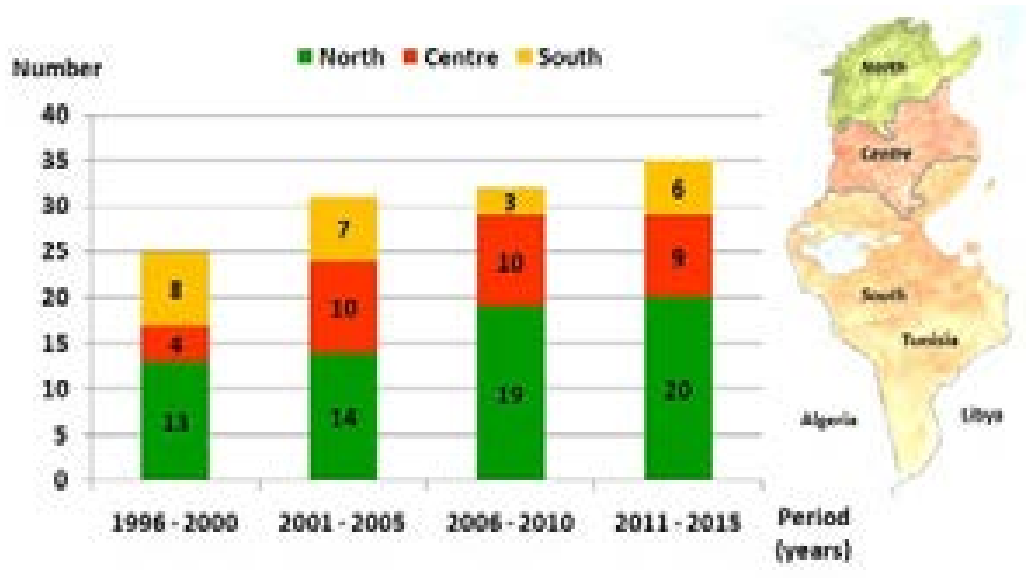

Figure 1: Cystic fibrosis incidence in Tunisia

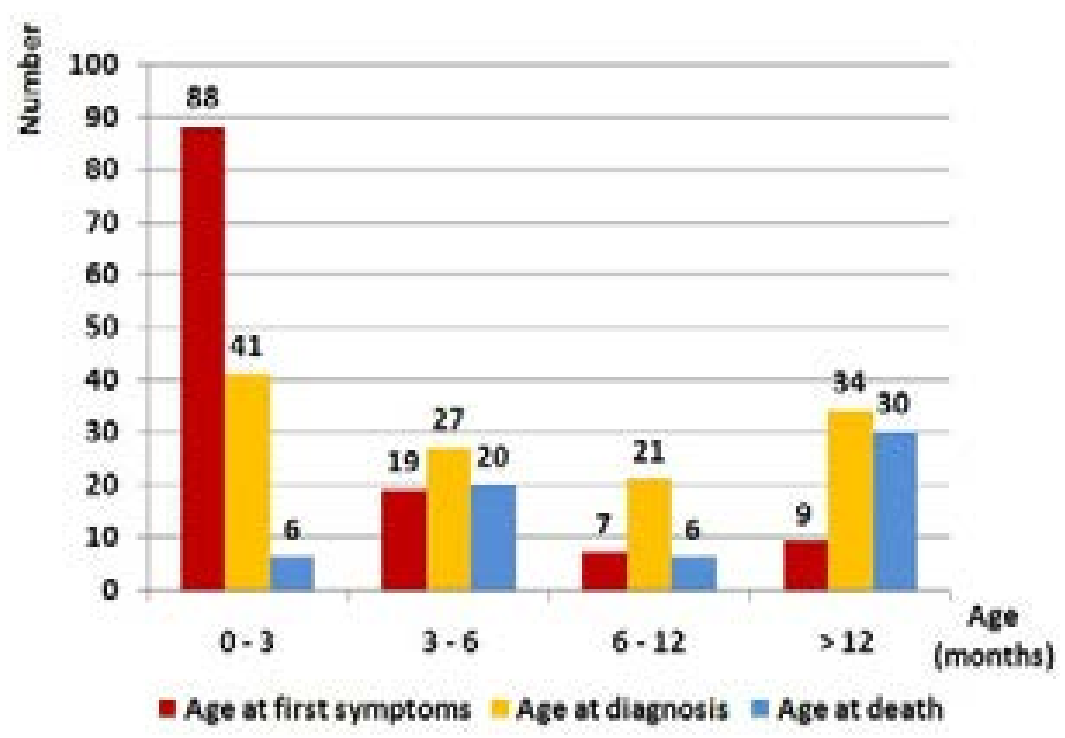

Figure 2: Demographics of the study population 


\section{Clinical profile and laboratory investigations}

$\mathrm{CF}$ was mostly revealed by recurrent or persistent respiratory tract infections $(n=86)$, denutrition $(n=68)$, chronic diarrhea $(n=51)$, and/or oedema with anemia and hypoproteinemia $(n=25)$. Other rare circumstances such as meconium ileus $(n=6)$, pseudo-bartter syndrome $(n=4)$, newborn screening due to an index case in the sibling $(\mathrm{n}=2)$, cholestatic jaundice $(\mathrm{n}=2)$, and small bowel atresia $(n=1)$ led to the diagnosis. The sweat test showed high values of sCl- (112.6 mmol/L on average [extremes: 60; 290 $\mathrm{mmol} / \mathrm{L}])$ in all the cases except in three cases where $\mathrm{sCl}$ - was equal to 36,45 and $55 \mathrm{mmol} / \mathrm{L}$. These three patients were homozygous for Phe508del (formerly F508del) mutation $(n=2)$ and G542X mutation $(n=1)$. Phe508del mutation was the most frequent mutation in our patients $(n=58)$ followed by E1104X mutation $(n=15)$. Three novel CFTR mutations (I1203V, $4268+2 \mathrm{~T}>\mathrm{G}$, and 3729 delA ins'TCT) were identified in four patients (Table 1). No mutation was found in 28 cases $(22.7 \%)$. In this population, genetic analysis was incomplete because of insufficient blood quantity to carry on the 27 -exon scanning and the failure to get a second blood sampling.

Table 1: Genetic analysis data in the study population

\begin{tabular}{|c|c|c|c|}
\hline CFTR gene mutation & Homozygous & Heterozygous & No. of patients \\
\hline Phe508del & 46 & 12 & 58 \\
\hline E1104X & 10 & 5 & 15 \\
\hline G542X & 3 & 5 & 8 \\
\hline N1303K & 4 & 2 & 6 \\
\hline $711+1 G>T$ & 2 & 2 & 4 \\
\hline W1282X & 2 & 1 & 3 \\
\hline $4268+2 \mathrm{~T}>\mathrm{G}$ & 2 & 0 & 2 \\
\hline G85E & 1 & 1 & 2 \\
\hline $1524+5$ InsC & 0 & 2 & 2 \\
\hline R764X & 1 & 0 & 1 \\
\hline R1158X & 1 & 0 & 1 \\
\hline I1203V & 1 & 0 & 1 \\
\hline 1677delTA & 1 & 0 & 1 \\
\hline del ex 1 ,et 2 & 0 & 1 & 1 \\
\hline R785X & 0 & 1 & 1 \\
\hline $\mathrm{R} 1066 \mathrm{C}$ & 0 & 1 & 1 \\
\hline 3729 delA insTCT & 0 & 1 & 1 \\
\hline Unknown & - & - & 28 \\
\hline
\end{tabular}




\section{Cystic fibrosis outcome Morbidity}

Seven patients $(5.7 \%)$ were lost to follow after the CF diagnosis. During the monitoring of the 116 patients, 64 patients $(55.1 \%)$ showed at least three respiratory tract infections or obstructive exacerbation per year. The most frequent isolated germ was Pseudomonas Aeruginosa $(\mathrm{n}=55)$ followed by Staphylococcus aureus $(\mathrm{n}=27)$, Haemophilus influenzae $(\mathrm{n}=22)$, and Klebsiella pneumoniae $(\mathrm{n}=21)$. The median age of $P$. Aeruginosa chronic colonization onset was 30 months [extremes: 3 months; 19 years]. Allergic bronchopulmonary aspergillosis affected three patients at the age of seven. Chronic respiratory failure occurred in 31 patients $(26.7 \%)$ at a median age of seven [extremes: 11 months; 15 years] (Table 2). Lung function tests performed in 24 patients showed proximal and distal airway obstruction $(n=15)$ and/or restrictive syndrome $(n=9)$. They were normal in five cases. Extra-respiratory disorders were dominated by hypotrophy (weight $<-2 \mathrm{SD}$ ) $(n=65)$ (Table 2). Cirrhosis and diabetes appeared at a mean age of 5.5 [extremes: 3; 8.5 years] and 12.5 [extremes: $10.5 ; 17$ years] respectively.

Table 2: The clinical course of cystic fibrosis in the followed patients $(n=116)$

\begin{tabular}{lll}
\hline Disorders during the monitoring & No. of patients & $\%$ \\
\hline
\end{tabular}

\section{Respiratory disorders:}

- Bronchiectatsis

- Pseudomonas Aeruginosa chronic colonization

- Chest wall depression or protrusion

- Clubbing

- Chronic respiratory failure

- Pulmonary arterial hypertension

- Hemoptysis

- Pneumothorax

- Allergic bronchopulmonary aspergillosis
3
57.8

47.4

32.8

31.9

26.7

8.6

7.8

3.4

2.6

\section{Extra-respiratory disorders:}

- Hypotrophy (weight $<-2 \mathrm{SD}$ )

65

15

4

4

4

2
56

3.4

3.4

1.7 


\section{Mortality}

Mean life expectancy was four years and ten months +/73SD. Sixty-two (53.4\%) patients died at a median age of eight months [extremes: 2 months; 23 years] due to a severe respiratory deficiency (Figure 1). Phe508del mutation in the homozygous state and hypotrophy were associated with death significantly and independently $(p=0.002$ and $\mathrm{p}<0.001$, respectively), hypotrophy being particularly associated with early death before the age of eight months $(p=0.014)$. For patients with CFTR mutation different from Phe508del $(n=37)$, they died more precociously than the other patients despite an earlier diagnosis (Table 3). For patients with unidentified mutation, compared to patients with identified CFTR mutation, the big diagnosis delay did not worsen the CF prognosis in terms of life expectancy and age of death. P. Aeruginosa chronic colonization was more frequent in patients who were homozygous for Phe508del mutation (Table 3). However, it wasn't associated with death either in these patients or in the study population ( $\mathrm{p}=0.3$ and $\mathrm{p}=0.17$, respectively).

Table 3: Characteristics of the study population according to cystic fibrosis genotype

\begin{tabular}{|c|c|c|c|c|}
\hline \multirow[b]{2}{*}{ Variables } & \multicolumn{4}{|c|}{ Genotype } \\
\hline & $\begin{array}{c}\text { Homozygous } \\
\text { for the } \\
\text { Phe508del } \\
\text { mutation }\end{array}$ & $\begin{array}{c}\text { Heterozygous } \\
\text { for the } \\
\text { Phe508del } \\
\text { mutation }\end{array}$ & $\begin{array}{c}\text { CFTR mutation } \\
\text { different from } \\
\text { Phe508del }\end{array}$ & $\begin{array}{c}\text { Patients with } \\
\text { unidentified } \\
\text { mutation }\end{array}$ \\
\hline No. of patients & 46 & 12 & 37 & 28 \\
\hline $\begin{array}{l}\text { Median age at first } \\
\text { symptoms (months) }\end{array}$ & 2 & 2 & 2 & 2.5 \\
\hline $\begin{array}{l}\text { Median age at } \\
\text { diagnosis (months) }\end{array}$ & 4.5 & 4.5 & 3 & 21 \\
\hline $\begin{array}{l}\text { No. of patients } \\
\text { missing during the } \\
\text { follow-up }\end{array}$ & 3 & 0 & 2 & 2 \\
\hline $\begin{array}{l}\text { Hypotrophy (weight } \\
<-2 \text { SD) }\end{array}$ & $28 / 43(65 \%)$ & $2 / 12(16 \%)$ & $23 / 35(65 \%)$ & $12 / 26(46 \%)$ \\
\hline $\begin{array}{l}\text { Pseudomonas } \\
\text { Aeruginosa chronic } \\
\text { colonization }\end{array}$ & $24 / 43(55 \%)$ & $5 / 12(41 \%)$ & $16 / 35(45 \%)$ & $10 / 26(38 \%)$ \\
\hline $\begin{array}{l}\text { Mean life } \\
\text { expectancy (years) }\end{array}$ & 4.8 & 4 & 3.6 & 7.2 \\
\hline Mortality rate & $31 / 43(72 \%)$ & $2 / 12(16 \%)$ & $19 / 35(54 \%)$ & $10 / 26(38 \%)$ \\
\hline $\begin{array}{l}\text { Median age of death } \\
\text { (months) }\end{array}$ & 7.5 & $\begin{array}{l}\text { (death at } 4 \text { and } \\
93 \text { months } \\
\text { respectively) }\end{array}$ & 5 & 84 \\
\hline
\end{tabular}

\section{Discussion}

This study showed that CF required a median time for diagnosis of three months although it was mostly revealed by classic symptoms such as: recurrent or persistent respiratory tract infections $(69.9 \%)$, denutrition $(55.2 \%)$, and/or chronic diarrhea (41.4\%). Mutation spectrum was variable with three novel CFTR mutations. However, genetic analysis failed to identify any mutation in 28 cases
(22.7\%). The most frequent mutations were Phe508del $(\mathrm{n}=58)$ and E1104X $(\mathrm{n}=15)$. P. Aeruginosa chronic colonization was frequent $(47.4 \%)$ especially among patients homozygous for Phe508del mutation (55\%). Though it occurred early (30 months), it didn't seem to precipitate patients' death $(\mathrm{p}=0.17)$. On the contrary, Phe508del mutation and hypotrophy were significantly associated with death $(\mathrm{p}=0.002$ and $\mathrm{p}<0.001$, respectively). 
Above all, this study revealed a low mean life expectancy (4.8 years +/-73SD) and an early median age of death (8 months) with a mortality rate of $53.4 \%$. It is dramatically different from current data in developed countries. According to the European CF Society (ECFS) patient registry in 2013, death in children aged less than five years was rare $(3.48 \%$ of the total deaths). The most frequent range of age of death was $21-30$ years $(36.23 \%)^{13}$ as seen in the United Kingdom (UK) ${ }^{14}$ and France ${ }^{15}$ where the median age of death was 29 and 31 years respectively. 'Tunisian data were comparable to Western-Europeans' in the 1970s. In fact, in Italy, in the 1970 s, $50 \%$ of deaths occurred within the first six months of life, whereas in the 2006-2011 period, the median age at death was 29 years and only $4 \%$ died in the first decade of life. ${ }^{16} \mathrm{CF}$ mortality in developing countries is variable with few available data. In Algeria, mortality rate was $48 \%$ among the $180 \mathrm{CF}$ patients registered until 2015. Their median age of death was two years. ${ }^{17}$ In a main referral center in Iran, over a 10-year period (1999-2008), 243 CF cases were diagnosed. Seven cases $(2.8 \%)$ died, all before the age of four years. ${ }^{18}$ Poor physiotherapy, lack of nutritional support, limited supply of specific therapies (enteric-coated pancreatic enzymes adapted to infants, inhaled antibiotics, recombinant human deoxyribonuclease (rhDNase)), in addition to poor organization of health care and insufficient social security, contributed to early death and poor growth in our patients.

CF incidence is estimated at 1/4500 live births in the Northern European population. With the introduction of newborn screening in Western countries, it is decreasing unlike CF prevalence which is increasing due to improvements in survival. ${ }^{19,20}$ In Tunisia, the exact CF incidence is difficult to determine. In fact, $\mathrm{CF}$ is still under-diagnosed because of the unavailability of the sweat test (except in two hospitals) and the insufficient awareness of the disease among primary care physicians, as shown by the rate of patients diagnosed after the age of six years (44.7\%) (Figure 2). Moreover, several cases potentially related to CF die rapidly before the diagnosis given the severity of the initial clinical condition and the difficulty of transfer to a university centre. In Algeria, a neighbouring country with four times our population and with the same difficulties, $180 \mathrm{CF}$ children were enrolled until $2015 .{ }^{17}$

Median age at CF diagnosis has improved in the developed countries especially where newborn screening programs have been implemented. In the Netherlands, in the 1990s the median age at diagnosis was 14 to 18 months. It was reduced to five months in 2008, then to 30 days with the introduction of newborn screening in May 2011, and all patients were diagnosed before the age of two months. ${ }^{21}$ In London and South Eastern England, the median age at diagnosis has decreased from 16.8 months in 2006 to 20 days in $2011 .^{22}$ In our series, the median age at diagnosis and the median time for diagnosis were five and three months respectively. In the Algerian study, first symptoms appeared at a mean age of three months and the median diagnosis delay was two years. ${ }^{17}$

CF diagnosis remains primarily clinical. In France, in 2013, apart from newborn screening, CF was revealed first by respiratory symptoms $(20 \%)$ then by meconium ileus $(9.1 \%) .{ }^{15}$ Dehydration was a rare circumstance of CF discovery in the total French CF patients (0.8\%). In Tunisia, the pseudo-bartter syndrome which associates dehydration, hyponatremia, hypochloremic and metabolic alkalosis, was present in four of our patients. Fustik et $\mathrm{al}^{23}$ found that early infant age, breast-feeding, delayed CF diagnosis, heat exhaustion and the presence of severe CFTR mutations predisposed for such metabolic disorders. These factors are consistent with the Tunisian context.

The sweat test is still the gold standard for confirming CF even if some non-CF conditions are associated with false positive sweat tests. Therefore, its interpretation should consider the context of the patient's clinical presentation. ${ }^{12}$ Identifying CFTR mutation is important for the $\mathrm{CF}$ diagnosis as well. It is indeed helpful in case of difficulties in performingor interpreting the sweat test, and useful for the antenatal screening. In addition, knowing the type of CFTR mutation class can partially explain the disease severity. It can also contribute to deciding for possible CFTR repair therapies. ${ }^{24,25}$ For all these reasons, more efforts should be made to reduce the percentage of unidentified mutations in our patients (22.7\%). In Latin American CF patients, this percentage was higher (37.2\%).26 While in France and the UK, 5.5\% and 8.9\% of $\mathrm{CF}$ patients respectively had at least one unknown genotype. ${ }^{14,15}$

The frequency of CFTR mutations varies considerably between countries and ethnic groups. In 18/23 European countries, $80 \%$ or more of the patients had at least one class II mutation including the Phe508del mutation, which was by far the most frequent mutation with

African Health Sciences Vol 20 Issue 1, March, 2020 
a higher proportion in Northern Europe compared to the southern. ${ }^{24}$ This mutation was less frequent among Arab populations.10,11 E1104X mutation, first described in a French-Canadian CF chromosome, was common in our study $(12.1 \%)$ as in Libyan patients $(40 \%) .{ }^{27}$ It is considered rare among $\mathrm{CF}$ worldwide patients and probably severe. The relatively high incidence of the E1104X mutation in both Tunisia and Lybia could be accounted for by common ancestry and migration between the two countries.

The CF lung disease can be evaluated by lung function tests or bacteriological markers such as $P$. aeruginosa colonization. In developed countries, systematic sputum examination monitoring and systematic $P$. aeruginosa eradication even in asymptomatic infants helped decrease this pathogen incidence. ${ }^{28}$ As in the UK, the incidence of P. aeruginosa chronic colonization declined in all age groups between 2008 and 2013 and reached 8.9\% in patients less than 16-year-old in 2013.14 In an Argentinian cohort of $83 \mathrm{CF}$ patients, with a mutation spectrum close to ours in the first most frequent mutations $\left(1^{\text {st }}\right.$ : Phe508del: $56.6 \%$; $2^{\text {nd }}$ : G542X: 4.2\%; 3rd: N1303K: 3\%), P. aeruginosa colonization was almost exclusively found in association with Phe508del mutation (14/16), ${ }^{29}$ unlike in our patients. A recent Polish study found that early $P$. aeruginosa chronic colonization was a predictor of lung function deterioration $(p=0.0165)$ among other risk factors (presentation of meconium ileus, impaired glucose tolerance, number of exacerbations), contrary to time of diagnosis and type of CFTR mutation. ${ }^{30}$ In Tunisia, lung function tests are difficult to perform in children due to their limited availability. Monitoring of the microbiology sputum examinations is often irregular and the analysis is limited to the exacerbation period.

One of the most significant changes in the CF epidemiology is the progress in survival in developed countries. In the United States, the median predicted survival increased from 28 years in 1990 to 38 years in 2010, and it is expected to reach 56 years for children born today. ${ }^{19}$ The clinical multidisciplinary care approach, the introduction of new therapeutics and health care systems have contributed to such improvements. In Europe, CF epidemiology trends are similar and the first cause of death remains CF respiratory disease $(70.61 \%){ }^{5,13}$ In Tunisia, hypotrophy was significantly associated with death $(p<0.001)$ especially in young infants $(p=0.014)$. Nutritional support should be a priority in CF management in Tunisia starting from the diagnosis.

\section{Conclusion}

In addition to providing more information about Tunisian national CF epidemiology and its position internationally, this study highlighted the insufficiencies with regard to the CF management given the severe CF prognosis in Tunisia. Initiating a national CF registry is the first necessary step stimulating our commitment to establish a single $\mathrm{CF}$ therapeutic strategy. Adequate care should definitely involve physicians, nurses, nutritionists, respiratory therapists, and social workers to achieve a better outcome.

\section{Limitations of the study}

We have supposed that all CF patients were followed-up in university hospitals since their diagnosis was usually established there. It is in fact an exception that a patient is followed only by a physician at a regional hospital or in a private practice. A few paediatric departments $(n=3)$ with one to three CF patients eachdid not participate in this study because of logistical difficulties.

\section{References}

1. O'Sullivan BP, Freedman SD. Cystic fibrosis. Lancet 2009;373:1891- PubMed ;904.

2. Parker-McGill K, Nugent M, Bersie R, Hoffman G, Rock M, Baker M, Farrell PM, Simpson P, Levy H. Changing Incidence of Cystic Fibrosis in Wisconsin, USA. Pediatr Pulmonol 2015;50:1065- PubMed ;1072.

3. Lakeman P, Gille JJ, Dankert-Roelse JE, Heijerman HG,Munck A, Iron A, Grasemann H, Schuster A, Cornel MC, Ten Kate LP. CFTR Mutations in Turkish and North African Cystic Fibrosis Patients in Europe: Implications for Screening. Genet Test 2008; 12:25-36 PubMed .

4. McCormick J, Green MW, Mehta G, Culross F, Mehta A. Demographics of the UK cystic fibrosis population: implications for neonatal screening. Eur J Hum Genet 2002;10:583- PubMed ;590.

5. Burgel PR, Bellis G, Olesen HV, Viviani L, Zolin A, Blasi F. Future trends in cystic fibrosis demography in 34 European countries. Eur Respir J 2015;46:133-41.

6. Fredj SH, Messaoud T, Templin C, des Georges M, Fattoum S, Claustres M. Cystic fibrosis transmembrane conductance regulator mutation spectrum in patients with cystic fibrosis in Tunisia. Genet Test Mol Biomarkers 2009;13:577-81.

7. Loumia O, Ferec C, Mercier B, Creff J, Fercot B, 
Denine R, Grangaud JP. CFTR mutations in the Algerian population. J Cyst Fibros 2008;7:54- PubMed ;59.

8. Shahin WA, Mehaney DA, El Falaki MM. Mutation spectrum of Egyptian children with cystic fibrosis. Springerplus 2016;5:686.

9. Rawashdeh M, Manal H. Cystic fibrosis in Arabs: a prototype from Jordan. Ann Trop Paediatr 2000;20:283-6 PubMed .

10. Farra C, Menassa R, Awwad J, Morel Y, Salameh P, Yazbeck N, Majdalani M, Wakim R, Yunis K, Mroueh S, et al. Mutational spectrum of cystic fibrosis in the Lebanese population J Cyst Fibros 2010;9:406-410.

11. Siryani I, Jama M, Rumman N, Marzouqa H, Kannan M, Lyon E, Hindiyeh M. Distributionof Cystic Fibrosis Transmembrane Conductance Regulator (CFTR) Mutations in a Cohort of Patients Residing in Palestine. PLoS One 2015;10:e0133890.

12. Guglani L, Stabel D, Weiner DJ. False-Positive and False-Negative Sweat Tests: Systematic Review of the Evidence. Pediatr Allergy Immunol Pulmonol 2015;28:198211.

13. Zolin A, McKone EF, van Rens J, Fox A, Iansa P, Pypops U, Gulmans V, Jung A, Cosgriff R, Mehta A, et al. ECFSPR Annual Report 2013, https://www.ecfs.eu/ projects/ecfs-patient-registry/annual-reports; 2016.

14. United Kingdom Cystic Fibrosis Registry. Annual data report 2013. http:// www. cysticfibrosis.org.uk/Registry; July 2014.

15. French Cystic Fibrosis Registry. Annual data report 2013. http:// www.vaincrelamuco.org/sites/default/ files/registre-2013.pdf; 2015.

16. Alicandro G, Frova L, Di Fraia G, Colombo C. Cystic fibrosis mortality trend in Italy from 1970 to 2011. J Cyst Fibros 2015;14:267- PubMed ;274.

17. Boukari R, Groupe d'étude sur mucoviscidose. Cystic fibrosis: course of management in Algeria. Arch Pediatr 2015;22:5-6 PubMed .

18. Fallahi G, Najafi M, Farhmand F, Bazvand F, Ahmadi M, Ahmadi F, Eftekhari K, Khodad A, Motamed F, Khatami G, et al. The clinical and laboratory manifestations of Iranian patients with cystic fibrosis. Turk J Pediatr 2010;52:132-138 PubMed .

19. Goss $\mathrm{CH}$. Country to country variation: what can be learnt from national cystic fibrosis registries? Curr Opin Pulm Med 2015;21:585-90 PubMed .

20. Spoonhower KA, Davis PB. Epidemiology of cystic fibrosis. Clin Chest Med 2016;37:1-8 PubMed .
21. Vernooij-van Langen AM, Gerzon FL, Loeber JG, Dompeling E, Dankert-Roelse JE. Differences in clinical condition and genotype at time of diagnosis of cystic fibrosis by newborn screening or by symptoms. Mol Genet Metab 2014;113:100-4 PubMed .

22. Lim MT, Wallis C, Price JF, Carr SB, Chavasse RJ, Shankar A, Seddon P, Balfour-Lynn IM. Diagnosis of cystic fibrosis in London and South East England before and after the introduction of newborn screening. Arch Dis Child 2014;99:197-202 PubMed .

23. Fustik S, Pop-Jordanova N, Slaveska N, Koceva S, Efremov G. Metabolic alkalosis with hypoelectrolytemia in infants with cystic fibrosis. Pediatr Int 2002;44:289-92 PubMed.

24. De Boeck K, Zolin A, Cuppens H, Olesen HV, Viviani L. The relative frequency of CFTR mutation classes in European patients with cystic fibrosis. J Cyst Fibros 2014;13:403-9 PubMed .

25. Wainwright CE, Elborn JS, Ramsey BW, Marigowda G, Huang X, Cipolli M, Colombo C, Davies JC, De Boeck $\mathrm{K}$, Flume PA, et al. Lumacaftor-Ivacaftor in patients with cystic fibrosis homozygous for Phe508del CFTR. N Engl J Med 2015;373:220- PubMed ;231.

26. Perez MM, Luna MC, Pivetta OH, Keyeux G. CFTR gene analysis in Latin American CF patients: heterogeneous origin and distribution of mutations across the continent. J Cyst Fibros 2007;6:194-208 PubMed .

27. Hadj Fredj S, Fattoum S, Chabchoub A, Messaoud T. First report of cystic fibrosis mutations in Libyan cystic fibrosis patients. Ann Hum Biol 2011;38:561- PubMed ;563.

28. Sermet-Gaudelus I, Mayell SJ, Southern KW; European Cystic Finrosis Society (ECFS), Neonatal Screening Working Group. Guidelines on the early management of infants diagnosed with cystic fibrosis following newborn screening. J Cyst Fibros 2010;9:323-9 PubMed .

29. Pepermans X, Mellado S, Chialina S, Wagener M, Gallardo L, Lande H, Bordino W, Baran D, Bours V, Leal T. Identification and frequencies of cystic fibrosis mutations in Ccentral Argentina. Clin Biochem 2016;49:154-60 PubMed .

30. Olszowiec-Chlebna M, Koniarek-Maniecka A, Stelmach W, Smejda K, Jerzyńska J, Majak P, Białas M, Stelmach I. Predictors of deterioration of lung function in Polish children with cystic fibrosis. Arch Med Sci 2016;12:402-7 PubMed . 